\title{
Euthyroid Graves' orbitopathy and incidental papillary thyroid microcarcinoma
}

\author{
Eugen Melcescu, ${ }^{1}$ William B. Horton, ${ }^{1}$ Karen T. Pitman, ${ }^{2,3}$ Vani Vijayakumar, ${ }^{3,4}$ \\ Christian A. Koch ${ }^{1,3,5}$
}

${ }^{1}$ Department of Medicine, ${ }^{2}$ Department of Otolaryngology, ${ }^{3}$ Cancer Institute, ${ }^{4}$ Department of Radiology / Nuclear Medicine, University of Mississippi Medical Center, ${ }^{5}$ Medical Service, G.V. (Sonny) Montgomery VA Medical Center, Jackson, MS, USA

\begin{abstract}
Euthyroid Graves' orbitopathy (GO) combined with incidental papillary thyroid microcarcinoma has rarely been reported. CASE REPORT: A 61-year-old Caucasian woman initially presented with progressive fatigue, exophthalmos, and thyroid function tests within normal limits. She underwent thyroidectomy, was found to have two incidental papillary thyroid microcarcinomas, and received radioactive iodine ablation to eliminate thyroid antigen. In addition to following her eye disease, TSH-receptor antibodies, thyroid stimulating immunoglobulins, and serum thyroglobulin measurements were recorded, demonstrating no evidence of thyroid cancer at four-year follow-up. At first, she had mild GO, developing into moderate-to-severe GO, and at 4 years she had Hertel measurements of $20 \mathrm{~mm}$ in both eyes. CONCLUSION: This report underscores the difficulty of managing GO even when thyroid function is normal(ized) and thyroid antigen exposure has been minimized. In addition, it illustrates why antithyroidal antibodies should be considered in cases of concomitant papillary thyroid cancer, as thyroid cells can be stimulated not only by TSH but also by TSH-receptor stimulating antibodies.
\end{abstract}

Key words: Antibody, Graves' disease, Orbitopathy, Radioactive iodine, Thyroid carcinoma

\section{INTRODUCTION}

Graves' orbitopathy (GO) is diagnosed in 10-25\%

\section{Address for correspondence:}

Prof. Dr. med. habil. Christian A. Koch, FACP, FACE,

Head, Endocrine Tumor Program, Cancer Institute, Director,

Division of Endocrinology, University of Mississippi Medical

Center, 2500 North State Street, University of Mississippi

Medical Center, Jackson, MS 39216, USA,

Tel.: +1-601-984-5495, Fax: +1-601-984-5769,

e-mail: ckoch@umc.edu

Received 04-01-2013, Accepted 09-05-2013 of patients with Graves' disease and a small percentage $(1.6-8.6 \%)$ of patients with GO are euthyroid or hypothyroid. ${ }^{1-5}$ As a multifactorial disorder, GO is influenced by non-preventable factors (age, sex, genetic factors) and exogenous factors (cigarette smoking, thyroid dysfunction, radioiodine treatment).,6

The pathogenesis of GO includes the TSH-receptor as an antigen, fibroblasts, and adipocytes as the main cell contributors, and a specific cytokine-mediated immunologic response. ${ }^{7,8}$ Patients with euthyroid 
Graves' disease and GO have high levels of TSH receptor antibodies (TRAb) including thyroid-blocking and thyroid-stimulating immunoglobulins (TSI). ${ }^{9,10}$

Cases of papillary thyroid microcarcinomas (PTMC) and concomitant euthyroid GO have previously been reported. ${ }^{11}$ Thyroidectomy specimens have been investigated for possible "incidentalomas" (thyroid microcarcinomas) in multiple studies, with prevalence rates up to $35.3 \% .{ }^{12-18} \mathrm{~A}$ few studies have concluded that papillary thyroid cancers (PTC) in Graves' disease patients have a more aggressive behavior due to the presence of high titers of thyroidstimulating antibodies. ${ }^{19-23}$ It is unclear whether the coexistence of differentiated thyroid cancer and thyroid autoimmune disorders such as Graves' and Hashimoto's disease has a causal relationship. ${ }^{23}$

A thorough investigation of patients with Graves' disease can help reduce the risk of missing some of these (incidental) thyroid cancers and other autoimmune disorders that might co-occur in the form of polyglandular syndrome variants..$^{24,25}$

\section{Case Presentation}

A 61-year-old Caucasian woman presented to her local primary care physician with a six-month history of progressive fatigue and exophthalmos. Initially, she was asymptomatic but remembered that a friend had commented about an enlargement of her eyes two months prior. She also noted double vision the days immediately before presentation. She described no change in the quality of her voice and denied any preceding stressful events, previous thyroid disease, radioactive iodine therapy, or (active or passive) smoking history along with problems related to eating, drinking or swallowing. Thyroid function tests performed at this time were within normal limits (Table 1). Orbital MRI demonstrated bilateral enlargement of the rectus muscle (inferior, medial, and superior), more prominent in the left orbit than in the right. This appearance was most suggestive of Graves' disease and associated orbitopathy. The patient consented to have pictures taken of her orbitopathy during visits. Figures 1A and 1B show her thyroid-associated orbitopathy on initial presentation.

The patient was then referred to our clinic and examined three months after initial presentation.
Over the previous three months, she had received prednisone therapy at $5 \mathrm{mg}$ every other day (prescribed by her ophthalmologist, for a total period of nine months). Laboratory studies now demonstrated a suppressed TSH, free T4, and anti-TPO antibodies within normal limits, elevated anti-TSH receptor antibodies, and undetectable thyroglobulin antibodies (Table 1). A thyroid ultrasound showed two bilobar nodules, each measuring approximately $15 \mathrm{~mm}$ in size, without increased vascularity or microcalcifications. Given her thyroid eye disease and the size of the thyroid nodules, a total thyroidectomy was scheduled to obtain definitive histology and reduce antigen-driven inflammation in the orbit. ${ }^{26}$

Before thyroid surgery, a detailed eye exam was performed. Visual acuity and Hertel measurements are shown in Table 1. No color vision errors, edema or pallor of the optic nerve were noted. Strabismus was appreciated as mild to moderate with intermittent diplopia. Total (subtotal) thyroidectomy was performed and considered successful, with less than 3-4 $\mathrm{g}$ of thyroid tissue remaining. The pathology report revealed a surprising finding of two conventional PTMCs measuring $0.5 \mathrm{~mm}$ and $2 \mathrm{~mm}$, respectively, in the right lobe within two mucoid nodules, 2 and $1 \mathrm{~cm}$ maximum dimensions, whereas the left lobe contained multiple benign nodules ranging from 1.1 to $1.5 \mathrm{~cm}$.

Our patient returned for another follow-up visit six weeks after surgery. Evaluation of thyroid function at this time demonstrated an elevated TSH, suppressed free T4, and elevated TSH receptor and anti-TPO antibodies (Table 1). She was diagnosed with postsurgical hypothyroidism and levothyroxine $100 \mathrm{mcg} /$ day was started. She also noted that her diplopia and blurred vision were worsening. At this point, we recommended radioactive iodine ablation to destroy any remaining thyroid tissue and further reduce antigen exposure. ${ }^{5,27}$

RAI ablation $(30 \mathrm{mCi})$ was performed and the patient returned for another follow-up exam. At this time, her TSH and TSH-receptor antibodies had decreased and anti-TPO antibodies were within normal limits (Table 1). Figures $1 \mathrm{C}$ and 1D show the patient's GO post-RAI ablation.

Although we were seeing improvement of thyroid function and antithyroidal antibody concentrations, 
Table 1. Biochemical and clinical analyses related to our patient's autoimmune thyroid disease over four years

\begin{tabular}{|c|c|c|c|c|c|c|c|c|c|c|}
\hline \multirow[b]{2}{*}{$\begin{array}{l}\text { Clinical } \\
\text { examination }\end{array}$} & \multicolumn{6}{|c|}{ Thyroid function tests } & \multirow[b]{2}{*}{ CAS } & \multirow[b]{2}{*}{ VISA } & \multirow[b]{2}{*}{$\begin{array}{l}\text { Visual } \\
\text { Acuity }\end{array}$} & \multirow[b]{2}{*}{$\begin{array}{c}\text { Hertel } \\
\text { Measurements } \\
(\mathbf{m m})\end{array}$} \\
\hline & $\begin{array}{c}\text { TSH } \\
(\mathrm{uU} / \mathrm{mL}) \\
\mathrm{N}: \mathbf{0 . 3 5}-\mathbf{4 . 5 0}\end{array}$ & $\begin{array}{c}\text { Free T4 } \\
(\text { ng/dL) } \\
\text { N: 0.89-1.76 }\end{array}$ & $\begin{array}{c}\text { Anti-TSH-R } \\
\mathrm{N}:<16 \%\end{array}$ & $\begin{array}{c}\text { TSI } \\
\text { N: } 0-1.3\end{array}$ & $\begin{array}{c}\text { Anti-TPO } \\
\text { (IU/ml) } \\
\text { N: } 0-9\end{array}$ & $\begin{array}{c}\mathrm{Tg} \\
(\mathrm{ng} / \mathrm{ml})\end{array}$ & & & & \\
\hline $03 / 2008$ (Initial) & 0.81 & 1.15 & - & - & - & - & - & - & - & - \\
\hline 06/2008 (Referral) & 0.035 & 1.7 & 44 & - & 9 & - & $2 / 7^{*}$ & $3 / 8^{* *}$ & $\begin{array}{l}\text { L: } 20 / 25 \\
\text { R: } 20 / 20\end{array}$ & $\begin{array}{l}\mathrm{L}: 21 \\
\mathrm{R}: 20\end{array}$ \\
\hline $\begin{array}{l}10 / 2008 \\
\text { (Post- } \\
\text { thyroidectomy) }\end{array}$ & $>100$ & 0.2 & 30 & - & 13 & 2.3 & - & - & - & - \\
\hline $\begin{array}{l}\text { 01/2009 } \\
\text { (Post-RAI) }\end{array}$ & 40.80 & - & 25 & - & 9 & $<0.1$ & - & - & - & - \\
\hline $\begin{array}{l}08 / 2009 \\
\text { (Post eye surgery) }\end{array}$ & 0.573 & - & 27 & - & - & $<0.1$ & $4 / 7^{1}$ & $6 / 8^{1}$ & - & $\begin{array}{l}\mathrm{L}: 26 \\
\mathrm{R}: 25\end{array}$ \\
\hline $12 / 2009$ & 0.087 & - & 5.42 & - & - & - & - & - & $\begin{array}{l}\text { L: } 20 / 25 \\
\text { R: } 20 / 25\end{array}$ & - \\
\hline $\begin{array}{l}07 / 2010 \\
\text { (Post left eye } \\
\text { surgery) }\end{array}$ & 0.136 & - & - & 2.5 & 8 & $<0.1$ & - & - & - & - \\
\hline 02/2011 & 1.550 & - & 3.14 & 3.2 & - & - & - & - & - & - \\
\hline 08/2011 & 0.44 & - & 2.09 & 1.9 & - & - & - & - & - & $\begin{array}{l}\text { L: } 20 \\
\text { R: } 20\end{array}$ \\
\hline $04 / 2012$ & 0.36 & - & - & 2.0 & - & $<0.1$ & $3 / 7$ & $4 / 8$ & - & $\begin{array}{l}\mathrm{L}: 20 \\
\mathrm{R}: 20\end{array}$ \\
\hline
\end{tabular}

* positive only for chemosis and eyelid edema, ** 2 points for chemosis and 1 point for eyelid edema

${ }^{1}$ these moderate to high scores may represent an initial increase in orbital inflammation due to trauma caused by eye surgery

CAS: Clinical Activity Score; VISA: vision, inflammation, strabismus, and appearance/exposure score, Tg: thyroglobulin.

Thyroglobulin antibodies were undetectable $(<20 \mathrm{IU} / \mathrm{ml}$ and $<1.8 \mathrm{IU} / \mathrm{ml})$ throughout her course of treatment from 2008 to 2012.

her diplopia continued to worsen and decompressive eye surgery was performed. She returned to our clinic for follow-up one month after surgery. At this time, her TSH was within normal limits, while TSH-receptor antibodies and Hertel measurements remained elevated (Table 1).

The decompressive eye surgery was successful for only a short period before the patient's condition worsened again, possibly as a result of surgical trauma to the orbit. She returned to us for another follow-up appointment six months following eye surgery. Visual acuity at this visit was stable (Table 1). No edema, pallor of the optic nerve or color vision errors were present. The patient noted worsening diplopia in her left eye and was scheduled for a second eye surgery.
Figures $1 \mathrm{E}$ and $1 \mathrm{~F}$ show the patient's GO on this visit.

We discussed intravenous glucocorticoid therapy according to the Kahaly protoco ${ }^{28}$ and radiotherapy but the patient was not in favor and, instead, underwent a second surgery on her left eye and returned for follow-up four months later. Her clinical presentation had improved at this visit and she noted that her diplopia had resolved. Figures $1 \mathrm{G}$ and $1 \mathrm{H}$ show her GO four months after left eye surgery. Table 1 shows laboratory studies drawn at this time.

We continued to monitor her GO and maintain surveillance for PTMC by regular follow-ups, serial thyroid function tests, serum thyroglobulin levels, and thyroid ultrasound examinations. We evaluated the 

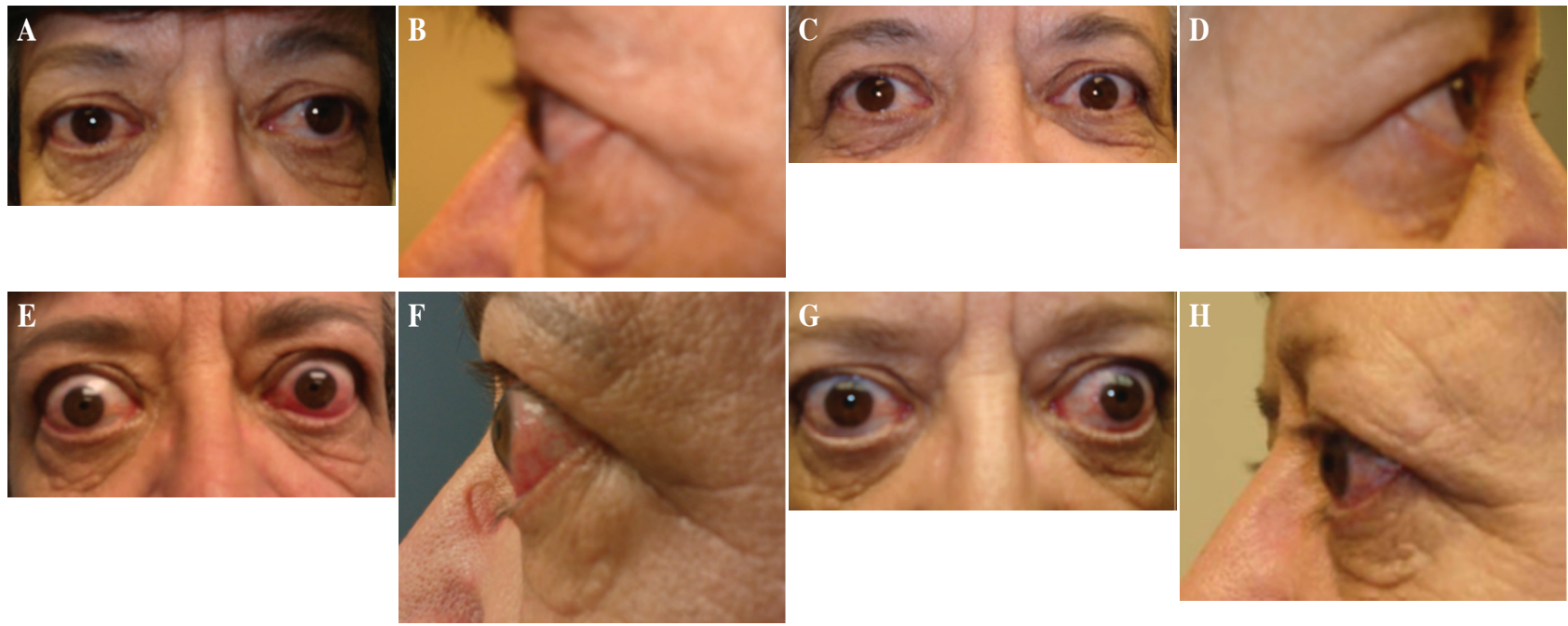

Figure 1. Anterior (A) and lateral (B) views of our patient's thyroid-associated orbitopathy on presentation. These images can be compared with anterior (C) and lateral (D) views of her TAO post-RAI ablation, anterior (E) and lateral (F) views six months after decompressive eye surgery, and anterior $(\mathbf{G})$ and lateral $(\mathbf{H})$ views four months after second eye surgery.

success of our treatment at various points throughout the patient's course by using the Clinical Activity Score (CAS) and VISA inflammatory score (Table 1). At her final follow-up visit four years after initial presentation, Hertel measurements were within normal limits and TSH was normalized (Table 1). Her GO showed significant improvement as demonstrated in Figures $2 \mathrm{~A}$ and $2 \mathrm{~B}$. She continues thyroid hormone replacement therapy with oral levothyroxine $200 \mathrm{mcg}$ daily.

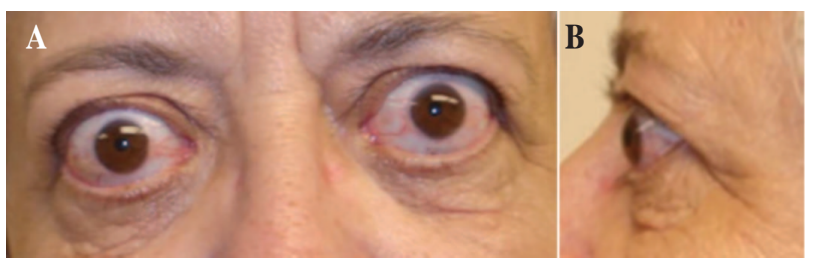

Figure 2. Anterior (A) and lateral (B) views of her thyroid-associated orbitopathy during final follow-up visit four years after initial presentation.

\section{DISCUSSION}

As only a small fraction of patients with GO are euthyroid at the time of presentation, our euthyroid patient, who denied any previous thyroid disease, radioactive iodine therapy, smoking history or preceding stressful events (environmental factors which have been identified as risk factors for exacerbation of Graves' disease ${ }^{6,29,30}$ ), is unusual. It is important to note her three-month prednisone therapy prior to referral visit, which could explain thyroid-function tests at referral (low TSH and FT4 within normal limits). ${ }^{31}$

The majority of GO cases appear in the context of hyperthyroidism. Luckily, severe GO occurs in less than $5 \%$ of patients with Graves' disease. In addition, it is very uncommon to have concomitant PTMCs, which can complicate the management of such patients, as radioactive iodine therapy usually is not recommended for patients with severe or moderate GO since it can aggravate the progression to orbitopathy. ${ }^{11,32}$ In assessing the chances of remission in patients with Graves' disease and/or GO, measuring autoantibodies is helpful. ${ }^{33,34}$ Thyroid-stimulating immunoglobulins (TSI) are very disease-specific with a detection rate of more than $90 \%$ in patients with Graves'disease., ${ }^{9,10,35}$ Whereas TSI is measured as an index in a bioassay that is very sensitive, unless there are very high TSI concentrations present (in which case a high-dose hook effect might occur), TSH-R antibodies are recorded in an assay measuring TSH-binding inhibition (TBII). Table 1 demonstrates how both assays compared for our patient, while also comparing both assays with serum levels of thyroglobulin in its function as a tumor marker. Euthyroid GO exists as a mixture between fluctuating amounts of thyroid-stimulating antibodies (measured by TSI) and thyroid-blocking 
antibodies (for which there is no direct assay commercially available). ${ }^{36-38}$ Thyroid-blocking antibodies are part of the TBII assay, though this assay is blind to the stimulatory or inhibitory nature of each anti$\mathrm{TSH}$-receptor antibody it measures. In the future, as more specific assays become commercially available, hopefully we will be able to elicit even more information about the biochemical basis for euthyroid GO.

Pazaitou-Panayiotou et al. reviewed the literature on thyroid cancer in patients with hyperthyroidism and found that most carcinomas associated with Graves' disease are small and found incidentally during postoperative histological evaluation of the thyroid..$^{39}$ They also concluded that microcarcinomas found in Graves' disease seldom cause metastases or recurrence, leaving the clinical significance of these microcarcinomas as uncertain. Our case correlates well with these findings, as both PTMCs were found incidentally on histological evaluation. These PTMCs did correspond with the thyroid nodules detected on ultrasound, though they occupied only a small portion of the nodules. Following total thyroidectomy and radioactive iodine ablation, our patient has remained free of any evidence of recurrence to this day. In a Scottish patient population with Graves' disease, administering $10 \mathrm{mCi}$ of radioactive iodine was as effective as $15 \mathrm{mCi}^{40}$ Interestingly, patients with Graves' disease and mild to moderate GO, those with large goiter or relapse of hyperthyroidism had had their hyperthyroidism and GO improved following total thyroidectomy alone. ${ }^{41,42}$ In retrospect, radioactive iodine ablation was necessary in our case, as multifocal tumors have been identified as a risk factor for high-risk or aggressive PTMC phenotype. ${ }^{43}$ For unifocal PTMC without risk factors, RAI ablation often is not necessary.

We utilized most of the treatment modalities available to cope with the undulant evolution of this case. Also, we investigated the possibility of employing new therapies such as rituximab (see http://clinicaltrials. gov/ct2/show/NCT00595335) or cyclosporine should her symptoms return. ${ }^{44,45}$ Recent research has shown that peroxisome proliferator-activated receptor- $\alpha$ $($ PPAR $\alpha$ ) agonists may exert immunomodulatory effects in GO by inhibiting various chemokines secreted by GO fibroblasts and preadipocytes. ${ }^{46,47}$ Perhaps addressing this pathogenic mechanism will help reduce the chance of disease recurrence in the future.

In conclusion, this case underscores the difficulty of treating GO even when thyroid function and antithyroidal antibodies are normal(ized) and thyroid antigen exposure has been minimized. Concomitant incidental papillary thyroid microcarcinoma can complicate management, as TSH-R stimulating antibodies may be present and, at times, TSH suppression may be desired making the patient hyperthyroid instead of euthyroid (the latter more desirable for GO).

\section{ACKNOWLEDGEMENT}

We thank John H. McVey, MD, Jackson Eye Associates, North State Street, Jackson, MS, for clinical care and collaboration on this patient.

\section{DISCLOSURE}

The authors have no financial conflict of interest with this report.

\section{REFERENCES}

1. Melcescu E, Horton WB, Kim D, et al, 2013 Graves' orbitopathy: update on diagnosis and therapy. South Med J: in press.

2. Khoo DH, Eng PH, Ho SC, et al, 2000 Graves' ophthalmopathy in the absence of elevated free thyroxine and triiodothyronine levels: prevalence, natural history, and thyrotropin receptor antibody levels. Thyroid 10: 1093-1100.

3. Marcocci C, Bartalena L, Bogazzi F, et al, 1989 Studies on the occurrence of ophthalmopathy in Graves' disease. Acta Endocrinol 120: 473-478.

4. Paunkovic J, Paunkovic N, 2006 Does autoantibodynegative Graves' disease exist? A second evaluation of the clinical diagnosis Horm Metab Res 38: 53-56.

5. Bartalena L, Tanda ML, 2009 Clinical practice. Graves' ophthalmopathy. New Engl J Med 360: 994-1001.

6. Pfeilschifter J, Ziegler R, 1996 Smoking and endocrine ophthalmopathy: impact of smoking severity and current vs lifetime cigarette consumption. Clin Endocrinol (Oxf) 45: 477-481.

7. Bahn RS, 2000 Understanding the immunology of Graves' ophthalmopathy. Is it an autoimmune disease? Endocrinol Metab Clin North Am 29: 287-296.

8. Bahn RS, 2010 Graves' ophthalmopathy. New Engl J Med 362: 726-738.

9. Lytton SD, Ponto KA, Kanitz M, et al, 2010 A novel thyroid stimulating immunoglobulin bioassay is a functional indicator of activity and severity of Graves' 
orbitopathy. J Clin Endocrinol Metab 95: 2123-2131.

10. Dragan LR, Seiff SR, Lee DC, 2006 Longitudinal correlation of thyroid-stimulating immunoglobulin with clinical activity of disease in thyroid-associated orbitopathy. Ophthal Plast Reconstr Surg 22: 13-19.

11. Duh QY, 2004 Thyroid cancer in Graves disease: incidental cancer versus clinical cancer. Ann Surg Oncol 11: 356-357.

12. Biscolla RP, Ugolini C, Sculli M, et al, 2004 Medullary and papillary tumors are frequently associated in the same thyroid gland without evidence of reciprocal influence in their biologic behavior. Thyroid 14: 946952.

13. Carlini M, Giovannini C, Castaldi F et al, 2005 High risk for microcarcinoma in thyroid benign diseases. Incidence in a one year period of total thyroidectomies. J Exp Clin Cancer Res 24: 231-236.

14. Dietlein M, Luyken WA, Schicha H, Larena-Avellaneda A, 2005 Incidental multifocal papillary microcarcinomas of the thyroid: is subtotal thyroidectomy combined with radioiodine ablation enough? Nucl Med Commun 26: 3-8.

15. Kovács GL, Gonda G, Vadász G, et al, 2005 Epidemiology of thyroid microcarcinoma found in autopsy series conducted in areas of different iodine intake. Thyroid 15: $152-157$.

16. Neuhold N, Kaiser H, Kaserer K, 2001 Latent carcinoma of the thyroid in Austria: a systematic autopsy study. Endocr Pathol 12: 23-31.

17. Harach HR, Franssila KO, Wasenius VM, 1985 Occult papillary carcinoma of the thyroid. A "normal" finding in Finland. A systemic autopsy study. Cancer 56: 531538.

18. Furlan JC, Rosen IB, 2004 Prognostic relevance of previous exposure to ionizing radiation in well-differentiated thyroid cancer. Langenbecks Arch Surg 389: 198-203.

19. Belfiore A, Garofalo MB, Giuffrida D, et al, 1990 Increased aggressiveness of thyroid cancer in patients with Graves' disease. J Clin Endocrinol Metab 70: 830-835.

20. Ozaki O, Ito K, Kobayashi K, et al, 1990 Thyroid carcinoma in Graves' disease. World J Surg 14: 437-440.

21. Mazzaferri EL, 1990 Thyroid cancer and Graves' disease. J Clin Endocrinol Metab 70: 826-829.

22. Pellegriti G, Belfiore A, Giuffrida D, et al, 1998 Outcome of differentiated thyroid cancer in Graves' patients. J Clin Endocrinol Metab 83: 2805-2809.

23. Feldt-Rasmussen U, Rasmussen AK, 2010 Autoimmunity in differentiated thyroid cancer: significance and related clinical problems. Hormones (Athens) 9:109-117.

24. Melcescu E, Hogan RB 2 ${ }^{\text {nd }}$, Brown K, et al, 2012 The various faces of autoimmune endocrinopathies: Nontumoral hypergastrinemia in a patient with lymphocytic colitis and chronic autoimmune gastritis. Exp Mol Pathol 93: 434-440.

25. Melcescu E, Kemp EH, Majithia V, et al, 2013 Graves' disease, hypoparathyroidism, systemic lupus erythe- matosus, alopecia, and angioedema: autoimmune polyglandular syndrome variant or coincidence? Int J Immunopathol Pharmacol 26: 237-242.

26. Nart A, Uslu A, Aykas A, et al, 2008 Total thyroidectomy for the treatment of recurrent Graves' disease with ophthalmopathy. Asian J Surg 31: 115-118.

27. Hautzel H, Pisar E, Yazdan-Doust N, et al, 2010 Qualitative and quantitative impact of protective glucorticoid therapy on the effective ${ }^{131} \mathrm{I}$ half-life in radioiodine therapy for Graves' disease. J Nucl Med 51: 1917-1922.

28. Kahaly GJ, Pitz S, Hommel G, Dittmar M, 2005 Randomized, single blind trial of intravenous versus oral steroid monotherapy in Graves' orbitopathy. J Clin Endocrinol Metab 90: 5234-5240.

29. Guarneri F, Benvenga S, 2007 Environmental factors and genetic background that interact to cause autoimmune thyroid disease. Curr Opin Enocrinol Diabetes Obes 14: 398-409.

30. Vita R, Lapa D, Trimarchi F, et al, 2009 A patient with stress-related onset and exacerbations of Graves disease. Nat Clin Pract Endocrinol Metab 5: 55-61.

31. Pantalone KM, Nasr C, 2010 Approach to a low TSH level: patience is a virtue. Cleve Clin J Med 77: 803811.

32. Antonelli A, Fallahi P, Tolari S, et al, 2008 Thyroidassociated ophthalmopathy and TSH receptor autoantibodies in nonmetastatic thyroid cancer after total thyroidectomy. Am J Med Sci 336: 288-290.

33. Schott M, Minich WB, Willenberg HS, et al, 2005 Relevance of TSH receptor stimulating and blocking autoantibody measurement for the prediction of relapse in Graves' disease. Horm Metab Res 37: 741-744.

34. Eckstein A, Esser J, Mann K, Schott M, 2010 Clinical value of TSH receptor antibodies measurement in patients with Graves' orbitopathy. Pediatr Endocrinol Rev 7: Suppl 2: 198-203.

35. Lytton SD, Li Y, Olivo PD, et al, 2010 Novel chimeric thyroid-stimulating hormone-receptor bioassay for thyroid-stimulating immunoglobulins. Clin Exp Immunol 162: 438-446.

36. Sarlis NJ, Brucker-Davis F, Swift JP, et al, 1997 Graves' disease following thyrotoxic painless thyroiditis. Analysis of antibody activities against the thyrotropin receptor in two cases. Thyroid 7: 829-836.

37. McLachlan SM, Rapoport B, 2013 Thyrotropin-blocking autoantibodies and thyroid-stimulating autoantibodies: potential mechanisms involved in the pendulum swinging from hypothyroidism to hyperthyroidism or vice versa. Thyroid 23: 14-24.

38. Martinez O, Gangi E, Mordi D, et al, 2007 Diversity in the complementarity-determining region 3 (CDR3) of antibodies from mice with evolving anti-thyroidstimulating hormone receptor antibody responses. Endocrinology 148: 752-761.

39. Pazaitou-Panayiotou K, Michalakis K, Paschke R, 2012 Thyroid cancer in patients with hyperthyroidism. Horm 
Metab Res 44: 255-262.

40. Collier A, Ghosh S, Hair M, et al, 2009 Comparison of two fixed activities of radioiodine therapy (370 vs. $555 \mathrm{MBq}$ ) in patients with Graves' disease. Hormones (Athens) 8: 273-278.

41. De Bellis A, Conzo G, Cennamo G, et al, 2012 Time course of Graves' ophthalmopathy after total thyroidectomy alone or followed by radioiodine therapy: a 2-year longitudinal study. Endocrine 41: 320-326.

42. Tamatea JA, Tu'akoi K, Conaglen JV, et al, 2012 Thyroid cancer in Graves' disease: is surgery the best treatment for Graves' disease? ANZ J Surg, http://dx.doi. org/10.1111/j.1445-2197.2012.06233.x

43. Durante C, Attard M, Torlontano M, et al, 2010 Identification and optimal postsurgical follow-up of patients with very low-risk papillary thyroid microcarcinomas. J Clin Endocrinol Metab 95: 4882-4888.
44. Madaschi S, Rossini A, Formenti I, et al, 2010 Treatment of thyroid-associated orbitopathy with rituximab- a novel therapy for an old disease: case report and literature review. Endocr Pract 16: 677-685.

45. Bartalena L, 2010 What to do for moderate-to-severe and active Graves' orbitopathy if glucocorticoids fail? Clin Endocrinol (Oxf) 73: 149-152.

46. Antonelli A, Ferrari SM, Frascerra S, et al, 2012 Peroxisome proliferator-activated receptor- $\alpha$ agonists modulate CXCL9 and CXCL11 chemokines in Graves' ophthalmopathy fibroblasts and preadipocytes. Mol Cell Endocinol 349: 255-261.

47. Antonelli A, Ferrari SM, Frascerra S, et al, $2012 \beta$ (CCL2) and $\alpha$ (CXCL10) chemokine modulations by cytokines and peroxisome proliferator-activated receptor- $\alpha$ agonists in Graves'ophthalmopathy. J Endocrinol 213: 183-191. 